Portland State University

PDXScholar

6-16-2021

\title{
Treatment Satisfaction and Self-Efficacy in Hispanic Diabetes Patients at a Free Clinic Setting
}

Lhanze Tum

Portland State University

Follow this and additional works at: https://pdxscholar.library.pdx.edu/honorstheses

Part of the Health Psychology Commons, and the Public Health Commons Let us know how access to this document benefits you.

\section{Recommended Citation}

Tum, Lhanze, "Treatment Satisfaction and Self-Efficacy in Hispanic Diabetes Patients at a Free Clinic Setting" (2021). University Honors Theses. Paper 1101.

https://doi.org/10.15760/honors.1128

This Thesis is brought to you for free and open access. It has been accepted for inclusion in University Honors Theses by an authorized administrator of PDXScholar. Please contact us if we can make this document more accessible: pdxscholar@pdx.edu. 
Treatment Satisfaction and Self-Efficacy in Hispanic Diabetes Patients at a Free Clinic Setting

\author{
by \\ Lhanze Tum
}

\begin{abstract}
An undergraduate honors thesis submitted in partial fulfillment of the requirements for the degree of

Bachelor of Science

in

University Honors

and
\end{abstract}

Public Health Studies: Clinical Health Sciences

Thesis Adviser

Dr. Claire Wheeler

Portland State University

2021 


\begin{abstract}
Diabetes continues to be one of the leading causes of death within the United States, with the Hispanic population having an especially high risk of developing diabetes. Understanding the different factors that may affect adherence to diabetes self-care, such as self-efficacy, duration of diabetes, and patient treatment satisfaction is important to reduce diabetes-related health complications. The aim of this study is to examine the relationship between patient self-efficacy for diabetes management and satisfaction with treatment, as well as whether the duration of diabetes is associated with self-efficacy for disease management. Baseline data was collected on 16 Hispanic patients with diabetes at a free clinic. Treatment satisfaction was measured using the Diabetes Treatment Satisfaction Questionnaire status (DTSQs) and self-efficacy was measured using the Perceived Diabetes Self-Management Scale (PDSMS). A significant positive correlation was found between diabetes treatment satisfaction (DTSQ) and self-efficacy (PDSMS). No significant relationship was found between duration of diabetes and self-efficacy. Our study results suggest that patients with high treatment satisfaction also have high selfefficacy levels, or vice versa. Diabetes healthcare providers looking to improve patient treatment satisfaction may benefit from implementing programs to improve patient self-efficacy. Conversely, healthcare providers looking to improve patient self-efficacy may benefit from addressing patients' treatment satisfaction.
\end{abstract}




\section{Treatment Satisfaction and Self-Efficacy in Hispanic Diabetes Patients at a Free Clinic}

\section{Setting}

Within the United States, diabetes continues to be one of the leading causes of death. According to the Centers for Disease Control and Prevention [CDC], about $10.5 \%$ of the United States population has diabetes (2020a). The prevalence of diabetes varies across different racial

and ethnic groups within the U.S., and ethnic minority groups such as non-White Hispanics tend to have one of the highest rates of diagnosed diabetes (12.5\%) compared to non-Hispanic Whites (7.5\%) (CDC, 2020b). With the Hispanic population having a high risk of developing diabetes, it is important to understand the different factors that may affect adherence to diabetes self-care, such as self-efficacy, duration of diabetes, and patient treatment satisfaction to reduce diabetesrelated health complications.

\section{Self-efficacy}

Patients play a large role in their diabetes health through self-management. Practicing diabetes self-management skills is vital to reducing morbidity and mortality risks associated with diabetes complications (Shrivastava et al., 2013). One of the best predictors for treatment adherence is self-efficacy (McCaul et al., 1987).

Self-efficacy is one's belief that they are capable of completing tasks that they set out to accomplish (Bandura, 1994). Based on the idea of self-efficacy as proposed by Albert Bandura, people will only complete tasks that they believe they are capable of and will avoid ones that they feel they are not capable of due to fear of failure. People with high self-efficacy will continue to persevere in the face of challenges because they believe that they will be able to conquer them, while those with low self-efficacy will lose confidence in themselves (Bandura, 1994). 
There are four different sources of self-efficacy development: 1. Performance accomplishments 2. Vicarious experience 3. Social persuasion 4. And physiological and emotional states (Bandura, 1994). Performance accomplishments refer to the experience of taking on a new challenge and completing it successfully. Having accomplished a task in the past builds confidence that one will be able to accomplish other tasks in the future as well. Selfefficacy can also be built through vicarious experience, in which one begins to believe in their abilities after observing someone similar to them succeed. Social persuasion through encouragement and support also adds to a person's self-efficacy. The last way in which selfefficacy is developed is through physiological and emotional states. If an individual is physically and emotionally healthy, they are more likely to have higher self-efficacy than if they were suffering from an illness such as depression (Bandura, 1977, 1994, 1997).

In a study conducted by Sarkar et al. (2006), they found that self-efficacy was significantly associated with self-care behaviors such as diet, exercise, self-monitoring of blood glucose, and foot care. Another study by Hurley and Shea (1992) found that patients with higher self-efficacy were able to manage their diabetes better. The participants' self-efficacy was measured following an intensive in-patient diabetes treatment, and about 30 days afterward the patients' diabetes self-care was measured. The results showed a significant positive correlation between self-efficacy and diabetes self-care (Hurley \& Shea, 1992).

\section{Duration of Diabetes}

A factor that may influence self-efficacy is the duration of diabetes. According to Bandura's concept of self-efficacy, one of the sources of self-efficacy development is performance accomplishments (Bandura, 1994). Depending on whether a patient has a history of accomplishments or failures in regards to their diabetes management, the duration of diabetes 
may be negatively or positively related to self-efficacy. In a study conducted by Dehghan et al. (2017) on patients in a diabetes clinic of Aq Qala city, North of Iran, they found a significant negative correlation between duration of diabetes and diabetes self-efficacy. Adwan and Najjar's study on diabetic clients in Amman city, Jordan also found that there was a low, but significant negative correlation between duration of diabetes and self-efficacy (Adwan \& Najjar, 2015). While the two previous studies found significant relationships between duration of diabetes and self-efficacy, a study by Wallston et al. (2007) found that they were uncorrelated and D'Souza et al. (2017) found that they were positively correlated. Research on the relationship between duration of diabetes and self-efficacy is limited, and the available research seems to have mixed results.

\section{Diabetes Treatment Satisfaction}

Another important factor in diabetes care is the patient's diabetes treatment satisfaction. Measuring diabetes patients' treatment satisfaction can help to determine the quality of care in the clinic and whether different treatment strategies are working (Saisho, 2018). Previous studies have found that patients reporting better adherence to lifestyle modification through diet and physical activity and/or medical therapy have higher diabetes treatment satisfaction (Saisho, 2018). Biderman et al.'s research found that lower treatment satisfaction was related to difficulties with diabetes treatment adherence and complications (Biderman et al., 2009). Evidence from these prior studies suggests a relationship between high treatment satisfaction and treatment adherence, or vice versa.

While there are studies relating diabetes treatment satisfaction to adherence and selfefficacy to adherence, there seems to be limited research on the relationship between treatment satisfaction and self-efficacy. This study has two main goals. First, to examine the relationship 
between patient self-efficacy for diabetes management and satisfaction with treatment. We expect to see that these two things vary together, in a positive correlation. Second, we seek to determine whether the time since diagnosis is associated with self-efficacy for disease management. Given mixed or scarce research on this question, we may see either a negative correlation or no correlation.

The terms Hispanic and Latino are often used interchangeably within the United States. While the term Hispanic refers to people with origins from Spanish speaking countries, Latino refers to those born in or with ancestors from Latin America ("What's the Difference Between Hispanic and Latino?" n.d.). For the sake of this paper, the term "Hispanic" will be used to refer to the study population since the focus is on populations that immigrated from a Spanish speaking country in Latin America. Also, the study participants most commonly used the term "Hispanic" to describe themselves.

\section{Methods}

\section{Study Setting}

This study was conducted at the Free Clinic of Southwest Washington, located in Vancouver, Washington. The Free Clinic of Southwest Washington is a donation-operated clinic that provides free medical care to the underserved and uninsured population in the Clark County area. The clinic recruits and employs many bilingual Spanish-speaking employees and volunteers to provide accessible care to Spanish-speaking patients.

\section{Study Participants}

The inclusion criteria for study participants were that they must speak Spanish as their primary language, be of Hispanic descent, 18 years or older, diagnosed with diabetes for at least one month prior to the study, and receive diabetes care at the Free Clinic for at least a month 
prior to the study. Patients enrolled in the Free Clinic's diabetes program that had appointments during March through mid-April of 2021 were asked to participate in the study. Patients that consented to the study $(n=16)$ were asked to answer demographic questions, as well as fill out the Diabetes Treatment Satisfaction Questionnaire and the Perceived Diabetes Self-Management Scale.

\section{Main Measures}

Patient's diabetes-related self-efficacy was measured using the Perceived Diabetes SelfManagement Scale (PDSMS). The PDSMS is an 8-item scale with the responses to each item ranging from 1 (Strongly Disagree) to 5 (Strongly Agree). Items \#1,2,6,7 were reverse-scored before adding up the total. The scores for the PDSMS ranged from 8-40, with a higher score indicating higher self-efficacy (Wallston et al., 2007).

Diabetes treatment satisfaction was measured using the Diabetes Treatment Satisfaction Questionnaire status version (DTSQs), which included 6 items that measured diabetes treatment satisfaction and 2 items that measured perceived hyperglycemia and hypoglycemia. For the sake of this study, the items relating to hyper/hypoglycemia were left out since we were only concerned with treatment satisfaction. The patients score each question on a scale of 0 (very dissatisfied, very inconvenient, etc...) to 6 (very satisfied, very convenient, etc...). Scores for the DTSQ total ranged from 0-36, with increased scores indicating increased diabetes treatment satisfaction (Bradley, 1994).

\section{Data Analysis}

Continuous and ordinal patient characteristics were summarized using mean \pm standard deviation and proportions were used for categorical variables. The relationship between diabetes treatment satisfaction (DTSQ) and self-efficacy (PDSMS), as well as the relationship between 
the duration of diabetes and self-efficacy (PDSMS), was analyzed using Spearman's rank correlation test. Correlations with p-value scores of less than 0.05 were considered significant.

\section{Results}

Sixteen patients with type 2 diabetes consented and participated in the study. Half of the participants were female $(n=8)$, the mean annual household income was $23,725 \pm 18107.07$ dollars, the mean age of the participants was $48.5 \pm 9.34$, and the average duration of diabetes was $8.33 \pm 6.67$ years [Table 1].

A significant positive correlation was found between diabetes treatment satisfaction (DTSQ) and self-efficacy (PDSMS). No significant relationship was found between duration of diabetes and self-efficacy [Table 2].

Table 1

Patient Characteristics.

\begin{tabular}{|c|c|}
\hline Variable & Mean \pm SD or n (\%) \\
\hline Age & $48.5 \pm 9.34$ \\
\hline Annual Household Income (Dollars) & $23,725 \pm 18107.07$ \\
\hline Duration of DM Diagnosis (Years) & $8.33 \pm 6.67$ \\
\hline Years Since Receiving Care at the Free Clinic & $2.66 \pm 2.21$ \\
\hline Diabetes Type 1 & $0(0 \%)$ \\
\hline Diabetes Type 2 & $16(100 \%)$ \\
\hline Female & $8(50 \%)$ \\
\hline Male & $8(50 \%)$ \\
\hline PDSMS Total & $31.44 \pm 6.59$ \\
\hline DTSQ Total & $32.25 \pm 4.64$ \\
\hline
\end{tabular}




\section{Table 2}

Association between diabetes treatment satisfaction and self-efficacy, and duration of diabetes and self-efficacy.

\begin{tabular}{|l|c|c|}
\hline Variable Relationships & $\begin{array}{l}\text { Spearman's Rank Coefficient } \\
\left(\mathrm{r}_{\mathrm{s}}\right)\end{array}$ & P-value \\
\hline DTSQ and PDSMS & 0.61763 & 0.01079 \\
\hline $\begin{array}{l}\text { Duration of Diabetes and } \\
\text { PDSMS }\end{array}$ & -0.43459 & 0.09254 \\
\hline
\end{tabular}

\section{Discussion}

This study found that diabetes treatment satisfaction and self-efficacy were positively correlated for the study sample of 16 Hispanic diabetes patients receiving care at a free clinic. Situating this result within previous literature is difficult due to the lack of research on the relationship between diabetes treatment satisfaction and self-efficacy. Diabetes treatment satisfaction and self-efficacy have individually shown to be positively related to self-care adherence in previous studies (Biderman et al., 2009; Hurley \& Shea, 1992; Saisho, 2018; Sarkar et al., 2006), so it is reasonable to expect that they may be positively correlated to each other as well.

This study did not find a significant correlation between duration of diabetes and selfefficacy, which is consistent with Wallston et al.'s (2007) study that determined the duration of diabetes and self-efficacy were uncorrelated. The results are inconsistent with Adwan and Najjar's study and Dehghan et al.'s study that found the two variables to be negatively correlated (Adwan \& Najjar, 2015; Dehghan et al., 2017). The results are also inconsistent with the positive correlation that D'Souza et al. (2017) found in their study. The varied results between duration of diabetes and self-efficacy in these studies may be attributed to the patients' experience of accomplishments or failures in self-management during the course of their diabetes. Going back 
to Bandura's concept of self-efficacy, a person with more accomplishments is going to have higher levels of self-efficacy, while someone that is experiencing failures is going to have lower levels of self-efficacy (Bandura, 1994). So, while one person may have higher self-efficacy due to the positive experiences they have in being able to manage their diabetes as time passes, another person's self-efficacy may decrease as time passes due to difficulties managing their diabetes. The other possibility is that there may not be any relationship between self-efficacy and duration of diabetes at all, but it is more likely that various factors like those mentioned here moderate this relationship.

Our study has several limitations, the first being that the sample size is small and can not detect small effect sizes, and does not allow for exploration of moderating variables. The second limitation is that the study relies on self-reported patient data. Another possible limitation is that the majority of the participants in the study were of Mexican descent, so the study results may vary for different Hispanic nationalities. The study population is similar to the clinic population with respect to gender and annual household income. Future research needs to be done on a larger population sample to detect small effect sizes and allow for exploration of moderating variables. Longitudinal studies using the DTSQ and the PDSMS would also be beneficial to determine which variable precedes the other.

\section{Conclusion}

It is essential for people with diabetes to acquire and practice diabetes self-management skills to reduce risk factors of morbidity and mortality associated with diabetes related complications. Our study found a significant positive relationship between diabetes treatment satisfaction and self-efficacy, and no significant relationship between duration of diabetes and self-efficacy. This information may be helpful for diabetes healthcare providers interested in 
improving patient satisfaction by focusing on programs aimed at self-efficacy, or inversely, if they are interested in improving self-efficacy it might be beneficial to address patients' satisfaction with their treatments. 


\section{References}

Adwan, M. A., \& Najjar, Y. W. (2013). The relationship between demographic variables and diabetes self-management in diabetic patients in Amman city/Jordan. Global Journal of Health Science, 5(2), 213-220. https://doi.org/10.5539/gjhs.v5n2p213

Bandura, A (1977). Self-efficacy: Toward a unifying theory of behavioral change. Psychological Review. 84 (2): 191-215.

Bandura, A. (1994). Self-efficacy. In V. S. Ramachaudran (Ed.), Encyclopedia of human behavior (Vol. 4, pp. 71-81). New York: Academic Press.

Bandura, A. (1997). Self-Efficacy: The Exercise of Control. New York: Freeman.

Bradley, C. (1994) The Diabetes Treatment Satisfaction Questionnaire: DTSQ. In Bradley C (Ed) Handbook of Psychology and Diabetes: a guide to psychological measurement in diabetes research and practice. Abingdon: Routledge ISBN 9783718655625, formerly published by Harwood Academic Publishers ISBN 3- 7186-5562-4: p.111-132.

Biderman, A., Noff, E., Harris, S. B., Friedman, N., \& Levy, A. (2009). Treatment satisfaction of diabetic patients: what are the contributing factors?. Family Practice, 26(2), 102-108. https://doi.org/10.1093/fampra/cmp007

Centers for Disease Control and Prevention. (2020a, August 28). National Diabetes Statistics Report, 2020. Retrieved from https://www.cdc.gov/diabetes/data/statisticsreport/index.html

Centers for Disease Control and Prevention. (2020b, June 25). Prevalence of Diagnosed Diabetes. Retrieved from https:/www.cdc.gov/diabetes/data/statistics-report/diagnoseddiabetes.html

Dehghan, H., Charkazi, A., Kouchaki, G. M., Zadeh, B. P., Dehghan, B. A., Matlabi, M., Mansourian, M., Qorbani, M., Safari, O., Pashaei, T., \& Mehr, B. R. (2017). General self- 
efficacy and diabetes management self-efficacy of diabetic patients referred to diabetes clinic of Aq Qala, North of Iran. Journal of Diabetes and Metabolic Disorders, 16, 8. https://doi.org/10.1186/s40200-016-0285-z

D'Souza, M. S., Karkada, S. N., Parahoo, K., Venkatesaperumal, R., Achora, S., \& Cayaban, A. (2017). Self-efficacy and self-care behaviours among adults with type 2 diabetes. Applied Nursing Research : ANR, 36, 25-32. https://doi.org/10.1016/j.apnr.2017.05.004

Hurley, A. C., \& Shea, C. A. (1992). Self-efficacy: strategy for enhancing diabetes self-care. The Diabetes Educator, 18(2), 146-150. https://doi.org/10.1177/014572179201800208

McCaul, K. D., Glasgow, R. E., \& Schafer, L. C. (1987). Diabetes regimen behaviors. Predicting adherence. Medical Care, 25(9), 868-881.

Saisho Y. (2018). Use of Diabetes Treatment Satisfaction Questionnaire in Diabetes Care: Importance of patient-reported outcomes. International Journal of Environmental Research and Public Health, 15(5), 947. https://doi.org/10.3390/ijerph15050947

Sarkar, U., Fisher, L., \& Schillinger, D. (2006). Is self-efficacy associated with diabetes selfmanagement across race/ethnicity and health literacy?. Diabetes Care, 29(4), 823-829. https://doi.org/10.2337/diacare.29.04.06.dc05-1615

Shrivastava, S. R., Shrivastava, P. S., \& Ramasamy, J. (2013). Role of self-care in management of diabetes mellitus. Journal of Diabetes and Metabolic Disorders, 12(1), 14. https://doi.org/10.1186/2251-6581-12-14

Wallston, K., Rothman, R., \& Cherrington, A. (2007). Psychometric properties of the Perceived Diabetes Self-Management Scale (PDSMS). Journal of Behavioral Medicine., 30(5), $395-401$.

What's the Difference Between Hispanic and Latino? (n.d.). Retrieved May 9, 2021, from https://www.britannica.com/story/whats-the-difference-between-hispanic-and-latino 